\title{
Estudos e Projetos de Próteses Ativas Enfatizando a Prototipagem Rápida
}

\author{
Studies and Projects of Active Prothesis Emphasizing the Quick Prototyping
}

\author{
Nilton Cardoso da Silva* \\ Universidade Estadual de São Paulo \\ Sorocaba - SP - CP 6051 - 13083-970 \\ Jorge Vicente Lopes da Silva \\ Instituto Tecnológico para Informática \\ Campinas - SP - CP 6162 - 13083-970 \\ João Maurício Rosário \\ Faculdade de Engenharia Mecânica - UNICAMP \\ Campinas - SP - CP 6051 - 13083-970
}

Este trabalho é relacionado com a engenharia de reabilitação, e mostra a evolução e a diversidade de formas e aplicações da física em algumas das técnicas de produção de próteses biomecânicas, seja na definição, construção e projeto da estrutura em seus diversos modelos, seja nos aspectos mecânicos, funcionais e operacionais, a exemplo da construção e do acionamento de próteses para indivíduos com amputação parcial dos membros superiores. $\mathrm{O}$ artigo apresenta a construção de dois modelos de próteses de apreensão. Um primeiro modelo do tipo acionamento com um atuador baseado em Shape Memory Alloy - SMA, é estudado através de três protótipos, um artesanal, um feito por usinagem convencional, e um terceiro por prototipagem rápida, sendo este último dedicado e integrado na estrutura da prótese. A proposta do segundo modelo, uma prótese acionada por motor de corrente contínua também é apresentada, sendo este integrado à garra, através de um redutor de velocidade. O projeto do modelo usando atuador baseado em SMA foi elaborado em CAD, observando que poucas alterações estruturais são necessárias na substituição deste atuador por um motor de corrente contínua.

\section{Palavras-chaves: Prototipagem Rápida, Membro Superior, Prótese Antropomórfica, Biomecânica.}

This work is related with the rehabilitation engineering, and shows the evolution and the diversity of forms and applications from Physics into some techniques for production of biomechanics prosthesis, be in the definition, construction and project of the structure in its many models, be in the mechanical, functional, operational aspects, as an example of construction and actuation of prosthesis for individual with partial amputation of upper limb. The article presents the construction of two models of prosthesis seizure. The first model, an actuation type, with the actuation based on Shape Memory Alloy - SMA, is studied through three prototypes, the first one handmade, a second one made by conventional machining and the third one by quick prototyping, the latter being dedicated and integrated into the structure of the prosthesis. The propose of the second model, a prosthesis throw by a direct current engine is also showed, being this integrated to the grip by a speed reducer. The project of the model using an actuator based on SMA was elaborated on CAD, observing that a few structural modifications are needed replacing the actuator by the direct current engine.

Key-words: Quick Prototyping, Upper Limb, Anthropomorphic Prosthesis, Biomechanics.

\footnotetext{
*Endereço Eletrônico: nilton157@yahoo.com.br
} 


\section{A QUESTÃo DAS PRÓtESES ANTROPOMÓRFICAS}

A maioria das deficiências físicas, são causadas por incidentes devido ao uso não apropriado de produtos da indústria que são usados para aumentar a força e a velocidade, enfim, a dinâmica do homem frente a modernização. As condições de uso destes produtos passam despercebidos por aqueles que ignoram que o futuro chegou, que vivem sem atentar para as normas de segurança sem considerar as limitações do homem que é frágil e mortal. Especificando as causas principais, encontramse os acidentes no trânsito, no trabalho, em esportes radicais, os conflitos pessoais decorrentes da marginalidade, as causas naturais, a má formação de origem genética e às doenças degenerativas e patogênicas. Estima-se que mais de $12 \%$ das pessoas no Brasil são portadoras de deficiências físicas, ou seja, mais de 19 milhões de pessoas.

Muitas vezes, o deficiente além de inativo, requer uma ou mais pessoas para se dedicar parcial ou exclusivamente a ele. Estas pessoas deixam de estar ativas para o crescimento social e econômico geral, sem contar o impacto psicológico emocional, e do preconceito e constrangimentos inerentes à deficiência que estes problemas, de uma forma geral, causam não só na vítima, mas em todos aqueles que convivem e dependem dele, especialmente sua família. Foi motivado por estas razões que surgiu o interesse pelo estudo destes problemas e buscouse o estudo e a fabricação de alguns protótipos de próteses antropomórficas.

Projetos de próteses envolvem não só o objeto que se pretende produzir, as próteses envolvem diversos ramos de aplicação da física como as engenharias elétrica, de controle, de automação, de software, mecânica, eletrônica etc. Uma prótese com sua mecânica, controle e acionamento embarcado [1] se integra ao sistema do qual ela fará parte, no caso o homem, e portanto seu corpo, seu comportamento físico, e psicológico e sua dinâmica e requer noções de outras áreas de conhecimento, tais como a fisiologia do sistema nervoso, que importa-se com o a coordenação dos movimentos e da postura [2], a anatomia [3, 4], a biomecânica [5], a psicologia e a estética. Este tipo de projeto é, portanto, fortemente multidisciplinar.

\section{PROPOSIÇÕes DESTE ARTIGo}

Este artigo concentra os estudos feitos e divulgados em diversos artigos, principalmente [6]8]. Este último apresenta especialmente as características físicas dos materiais termofundíveis usados. A pretensão aqui é mostrar a evolução da fase de prototipagem desenvolvida nestes dois últimos dois anos, discriminando as diversas fases deste programa até o presente, começando com a validação dos modelos antropomórficos e a produção estrutural de alguns protótipos de próteses, onde trabalhamos de forma artesanal a usinagem e, finalmente, a prototipagem rápida. A evolução deste estudo será mostrada através dos projetos realizados, desde os mais simples e rústicos até os projetos funcionais e, portanto, mais sofisticados e que representam passos importantes alcançados.

O primeiro projeto mencionado será o de um modelo de membro superior antropomórfico completo, utilizando articulações básicas do tipo cilíndricas com o cotovelo acionado por um atuador pneumático através de um cabo. O segundo projeto, análogo ao primeiro, trata-se do protótipo do aparelho locomotor antropomórfico completo, construído de forma análoga ao primeiro, porém visando o estudo de movimentos coordenados.

O terceiro projeto, mais complexo que os demais, baseado em [1], trata-se da construção estrutural de uma prótese funcional acionada por atuador a SMA, a qual é dividida em três etapas: uma de pré-prototipagem, onde um protótipo artesanal é construído para estudo do mecanismo, a outra que culmina com a definição de um projeto para construção de peças por usinagem. E a última, onde realizamos a otimização do projeto original visando a produção de uma estrutura através do processo de prototipagem rápida. Finalmente, apresentamos dois projetos idealizados: um onde o a- 
tuador desta última prótese é substituído por um motor elétrico, e outro de um soquete para o acoplamento da prótese ao braço amputado utilizando prototipagem rápida.

\section{METODOLOGIAS DIVERSAS UTILIZADAS NO PROJETO DE PRÓTESES}

Esta seção mostra a evolução da busca de metodologias para produção e estudos de próteses antropomórficas. Aqui a modelagem, validação e prototipagem de modelos dos membros inferiores e superiores antropomórficos são enfatizada. Em seguida, destacamos a evolução do projeto da estrutura de uma prótese antropomórfica, passando pela validação e estudo de um modelo artesanal baseado no modelo apresentado por [1], seguido da remodelagem do programa deste o projeto para posterior usinagem até, finalmente, sua redefinição visando a utilização do processo de prototipagem rápida.

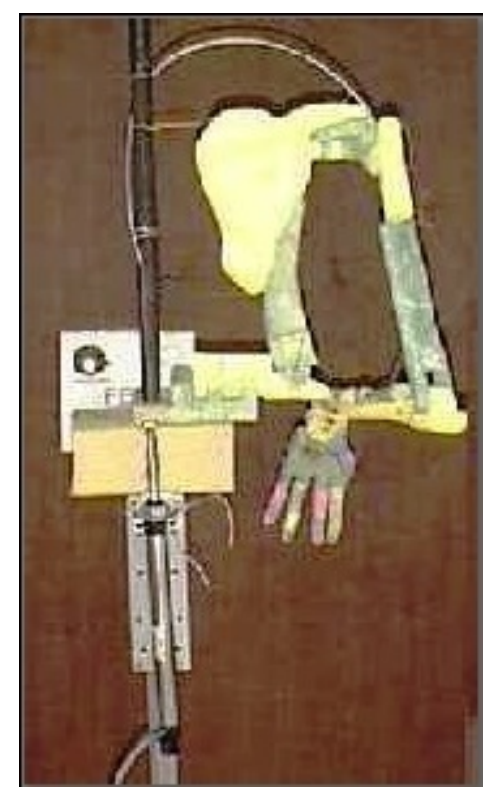

FIGURA 1: Protótipos dos membros antropomórficos completos: superiores.

\section{A. Histórico da modelagem dos membros Antropomórficos}

Para a definição da modelagem antropomórfica foi utilizado, neste trabalho, o estudo da anatomia humana baseado em [3, 4], da biomecânica [5] e das transformações homogêneas e cinemática direta, acionamento, e controle utilizadas em robótica conforme se pode constatar em [911.

$\mathrm{Na}$ área de modelagem antropomórfica já foram publicados diversos artigos relacionados com a cinemática [12 14]. Assim, após a decomposição das complexas articulações ou juntas esféricas antropomórficas em simples articulações cilíndricas, conforme [14] podemos utilizar as técnicas de modelagem de robôs. Após isto, a adaptação estrutural do modelo antropomórfico e o estabelecimento de uma técnica de simplificação da identificação dos parâmetros do modelo chamado Sistema de Coordenadas Intermediário, definimos o modelo completo. Uma vez que o modelo antropomórfico tenha sido completado, constrói-se duas estruturas para verificação e validação do modelo envolvendo as partes mais complexas e genéricas do mesmo: os membros inferiores e o membro superior, visando o estudo do emprego de atuadores do tipo pneumático para acioná-los bem como a coordenação de movimentos.

\section{B. Estudo e Validação do Modelo dos Membros}

Iniciamos este trabalho com a validação dos graus de liberdades antropomórficos e o primeiro destacado aqui é o modelo dos membros superiores antropomórfico, como mostra a Figura (1). Neste caso, os elos foram produzidos artesanalmente tendo como material básico isopor reforçado internamente por tiras de madeira e nas juntas por tubos de PVC, com eixos de metal, no caso aço. Cada uma das juntas foi decomposta em cilíndros, para facilitar a modelagem e simplificar a construção. Este 
tipo de trabalho utiliza um atuador pneumático para acionamento de cada junta, separado do corpo do protótipo, e transfere movimentos e forças para a junta do cotovelo através de um cabo de aço fino e que passa dentro de um tubo de plástico flexível, de maneira que o cilindro pneumático quando é recolhido, traciona o cabo e fecha o cotovelo.

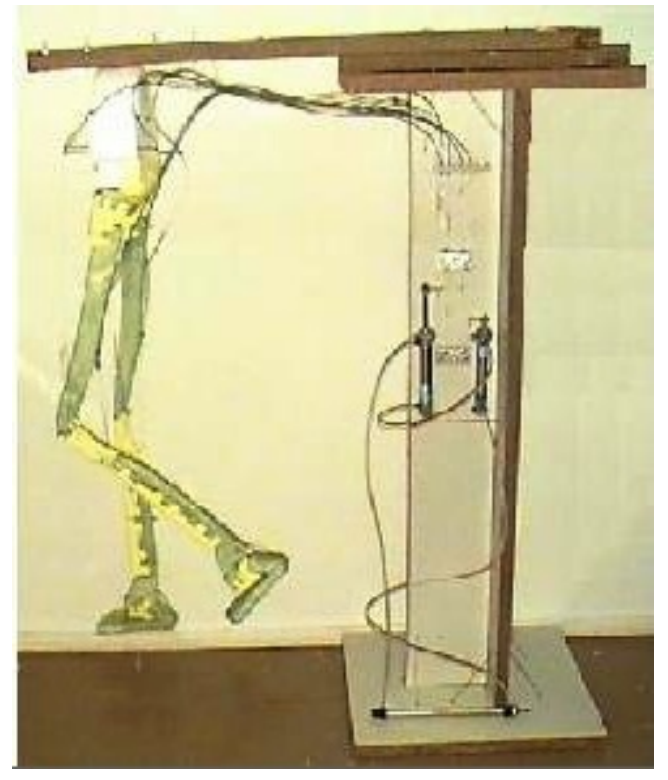

FIGURA 2: Protótipos dos membros antropomórficos completos: inferiores.

Destacamos agora o protótipo de um par de membros inferiores, Figura (2), construído de forma análoga ao do membro superior. Neste caso, no entanto, o objetivo foi estudar a coordenação dos movimentos utilizando atuadores para articular os joelhos e flexionar e estender as coxas, simulando alguns tipos de marchas humanas. O protótipo é fixado por um eixo que o atravessa frontalmente da parte anterior para a parte posterior, em torno do qual a estrutura do conjunto oscila, produzindo um efeito semelhante ao do requebrar do quadril. Entre o atuador e a junta acionada, além do cabo e seu tubo direcionador, encontra-se um dispositivo que permite inverter o movimento do atuador e derivar um cabo que produz na coxa oposta um movimento antagônico, quando a primeira é tracionada. Isto economiza dois atuadores para fazer os movimentos de extensão da coxa, muito embora não permita movimentos isolados e unidirecionais das duas coxas.

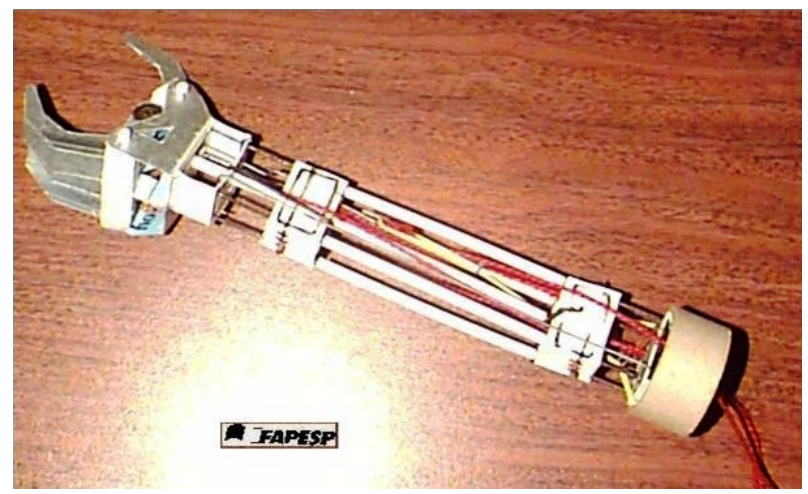

FIGURA 3: Protótipo de validação do mecanismo de uma prótese artesanal para crianças.

\section{Desenvolvimento de um Protótipo de Prótese para suportar um atuador a SMA}

Os protótipos apresentados até aqui tinham apenas a função de validar e modelos antropomórficos e estudar a estrutura e sua interferência nos movimentos e graus de liberdade. Mas o objetivo final deste programa é a fabricação de modelos de próteses ativas reais. Diversos trabalhos são conhecidos, mas são complexos e cheios de incógnitas [15] e [16]. Foi na tese de doutorado de Soares [1, sobre próteses acionadas metais com memória com forma SMA, que encontramos bons modelos e resultados práticos para servir de referência a este trabalho.

\section{Análise Funcional do Protótipo}

A partir desta decisão foi planejado um estudo em três fases: compreensão do mecanismo, reprodução do mecanismo e otimização do mesmo, ou seja, da estrutura ou chassi da prótese objetivando a obtenção de novas possibilidades de pesquisas. As quatro contribuições deste trabalho são: o domínio e a modernização do processo de fabricação da estrutura, a descoberta de novos materiais e a implementação 
do controle utilizando lógica programável [17, e com isso abrindo caminho para a alteração da forma de acionamento.

$\mathrm{Na}$ fase do estudo e compreensão do mecanismo, foi produzido um protótipo artesanal, a partir de papelão, arames, fios de lã, elástico e PVC, conforme ilustrado pela Figura (3). Neste protótipo, os dedos em número de quatro, fixos num eixo comum, são acionados em oposição ao polegar, como as lâminas de uma tesoura. Neste caso, uma borracha substituindo o efeito de uma mola traciona os dedos para trás, enquanto que os fios de lã quando puxados sofrem inversão de movimento ao passar por uma roldana ou rolete, e podem produzir o efeito dos fios de SMA quando tracionados por trás, empurrando para frente um embolo que abre a garra. Isto permite verificar o processo e o modelo do dispositivo com clareza, bem como sugere inovações no mecanismo.

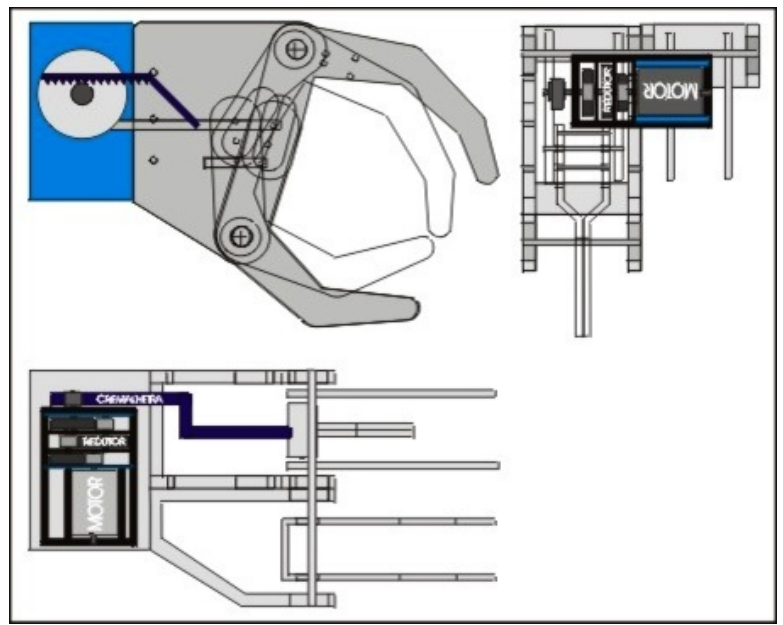

FIGURA 4: Projeto e peças de protótipos produzidas por usinagem do alumínio - Parte I.

\section{A prototipagem de próteses funcionais acionada a motores e a SMA, por usinagem e prensagem}

$\mathrm{Na}$ fase de reprodução do mecanismo elaboramos dois projetos de prótese de apreensão de ação planar com quatro dedos inativos e um ativo e, em seguida, enviamos para a oficina mecânica objetivando o torneamento das peças para montagem posterior, veja Figuras (4, 5). Neste caso, as máquinas utilizadas foram prensas e tornos convencionais e fizemos algumas intervenções manuais para a construção de alguns detalhes. Durante a usinagem das peças e montagem do protótipo final, alguns ajustes e um novo projeto das peças ou dos mecanismos completos foram necessários para eliminar áreas de fragilidade e com má operação.

\section{A prototipagem rápida}

Por que a prototipagem rápida pode ser de interesse para a Física? A resposta está na complexidade do equipamento utilizado e que será descrito posteriormente. Este equipamento envolve controle por comutadores de intensidade e precisão da óptica, produção de raio laser, estudo de materiais termofundíveis e, portanto, termodinâmica e robótica para o direcionamento deste laser.

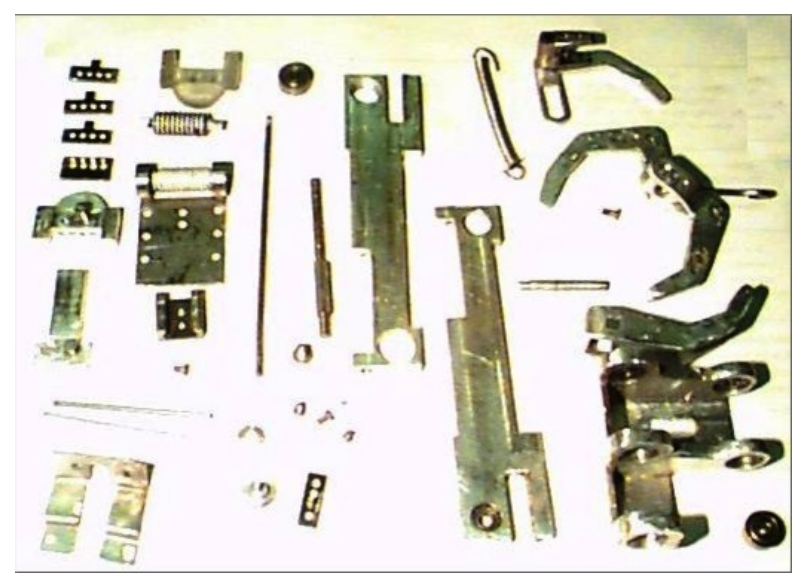

FIGURA 5: Projeto e peças de protótipos produzidas por usinagem do alumínio - Parte II.

\section{Prototipagem Rápida de uma Prótese a ser acionada por SMA (Projeto utilizando $C A D)$}

As ligas de memórias de forma, ou SMA, são exemplos de oportunidades criadas pela 
física atual e destacam materiais que são constituídos de ligas, definidas em certos estados, de tal forma que após deformadas ou alongadas por alguma tração tendem a voltar para a conformação do estado original quando aquecidas por efeito Joule em temperaturas definidas. Elas merecem um estudo a parte. Mas destacaremos aqui que elas são interessantes para o uso em próteses, porque atuam linearmente como músculos artificiais com grande capacidade de força e rendimento maior que um músculo biológico, embora atualmente tenham uma resposta lenta. Elas requerem uma estrutura reforçada, e que suporte fios aquecidos a consideráveis temperaturas, daí o cuidado e estudo da prototipagem rápida e seus materiais para a aplicação em próteses.

A prototipagem rápida permite a criação de peças complexas na geometria e, às vezes, não factíveis por processos convencionais como a usinagem. As próximas etapas visam a criação de peças por prototipagem rápida, desde a concepção da estrutura da prótese em um modelador sólido até à obtenção final pelo processo SLS, Modelagem de sólidos, Representação por Malha de Triângulos, e Sinterização a Laser.

A base para utilização de tecnologias de prototipagem rápida é a modelagem de cada peça de uma prótese através de um sistema CAD com capacidade de modelagem sólida ou de superfícies fechadas. As várias peças que compõem a prótese foram geradas utilizando um modelador sólido, com o objetivo de otimizar o tempo para a construção e obter modelos consistentes para a prototipagem.

Os modelos gerados devem ser exportados em um formato específico para a prototipagem, cuja representação do sólido é feita através de uma malha de triângulos com o vetor normal apontando na direção contrária do material. Uma vez exportado o arquivo na representação de triângulos, este deve ser verificado por ferramentas que permitem a análise da consistência do modelo verificando, entre outros, a presença de triângulos invertidos ou duplicados e vãos ou aberturas na estrutura da malha.

O processo de prototipagem rápida utilizado para a construção da prótese foi a Sinterização Seletiva a Laser (SLS). Na SLS a superfície de um modelo é gerada num programa de CAD no computador em malhas triangulares após o que é fatiada em seções de aproximadamente $0,1 \mathrm{~mm}$ de espessura, na camada de pó espalhada num recipiente. Depois, um feixe de laser risca e aquece as seções da peça na camada de pó de polímero termoplástico depositada, camada por camada, sucessivamente, integrandoas ao corpo do protótipo até que a peça esteja completa.

\section{O processo da prototipagem rápida}

Neste item, os tópicos apresentados anteriormente são discutidos com mais detalhes quanto aos resultados da aplicação do processo de prototipagem rápida na confecção do protótipo mencionado. Especificamente, trataremos da construção da prótese usando a modelagem de sólidos; da apresentação das propriedades do material usado na prótese; do processo de exportação de dados e ferramentas para prototipagem rápida da prótese; da montagem do build que antecede o desencadeamento do processo de STL e, finalmente, do acabamento e a montagem da prótese.

\section{Modelagem e simulação das peças da prótese}

A evolução dos sistemas de modelagem geométrica tem sido muito grande na última década, juntamente com a acentuada evolução na capacidade de processamento dos computadores. Isto implicou na melhoria de funcionalidade e eficiência das interfaces homemmáquina, na forma como modelar a geometria dos objetos, aumentando o realismo nas representações da geometria, nas possibilidades de simulações dinâmicas e na análise de interferências. Isto permitiu também a exportação de dados em padrões que fomentam a interoperabilidade entre sistemas CAD distintos, implicando em grande popularização dos sistemas CAD e em grandes incentivos à sua evolução. 
Uma etapa fundamental que precede a prototipagem rápida é a utilização de modeladores sólidos ou de superfícies fechadas com os quais podemos obter modelos consistentes e factíveis. Na Figura (6) mostramos as peças da prótese obtidas com a utilização de um modelador CAD sólido. As peças assim modeladas permitem a junção e simulação do funcionamento e verificação de incoerências da estrutura.

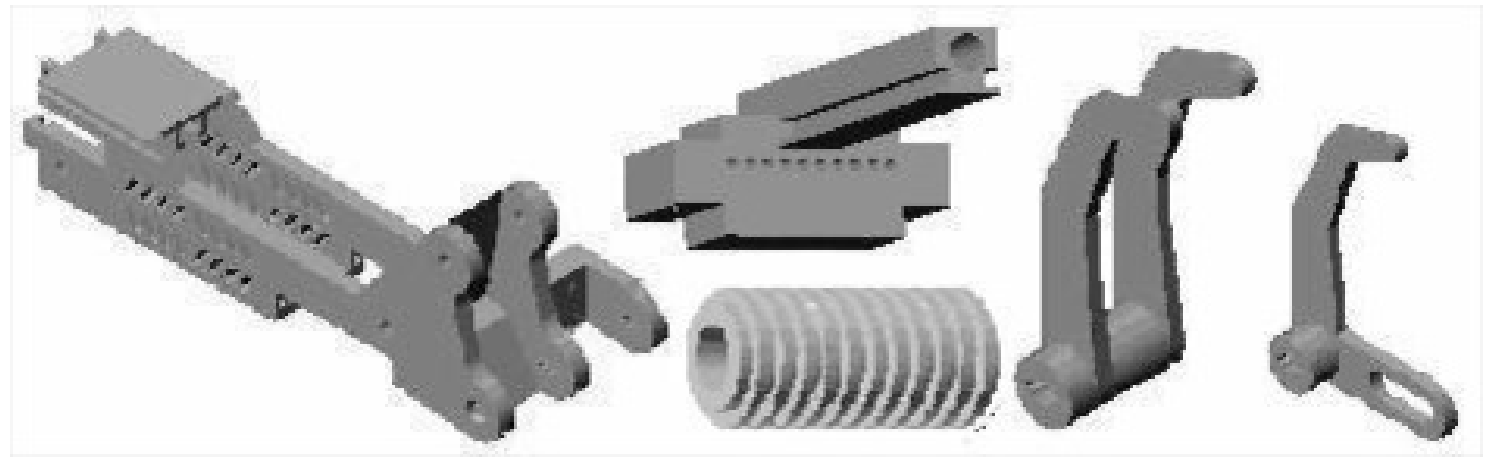

FIGURA 6: Modelo em CAD das peças da prótese a SMA.

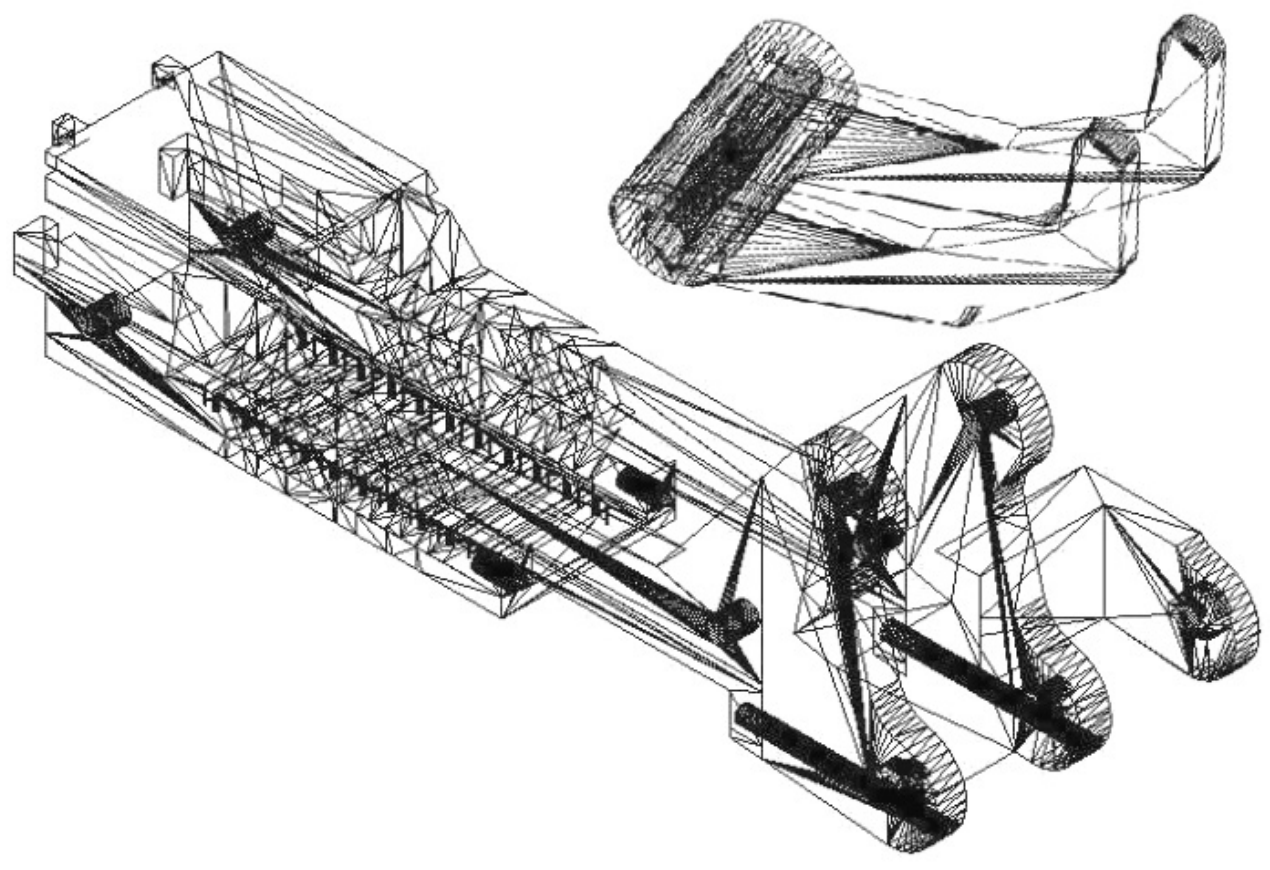

FIGURA 7: Modelo do chassi da prótese representado por malha de triângulos.

\section{Propriedades dos materiais de prototipagem}

A maior limitação das tecnologias de prototipagem rápida está nos materiais usados na construção dos protótipos físicos que são, geralmente, caros e diferentes do produto final. É necessário que as pesquisas avancem neste campo de modo a preencher esta lacuna de forma satisfatória. Outra limitação é a dificuldade de produzir peças muito pequenas ou muito grandes. O primeiro problema é devido à resolução ou precisão dos sistemas de 
prototipagem rápida existentes. Peças muito grandes podem ser simuladas em computadores sem dificuldades, mas visto que as tecnologias de fabricação por prototipagem rápida são limitadas em tamanho, grandes peças têm que ser cortadas e, então, montadas posteriormente. Pesquisa também é necessária para aprimorar as tecnologias de prototipagem rápida existentes em termos de precisão e capacidade de produção.

Para o desenvolvimento e estudo da prótese deste trabalho foi utilizado o material $\mathrm{Du}$ raform Polyamide, patenteado pela empresa DTMTM Corporation para o processo SLS. Este material é um membro da família do $\mathrm{Ny}$ lon com propriedades mecânicas equivalentes à dos plásticos utilizados para injeção. As propriedades deste material fornecidas pela DTMTM são baseadas em teste realizados em laboratórios especializados e independentes. Uma ressalva que fazemos é sobre a utilização de parâmetros de processos, em especial, da maior potência de laser na construção dos corpos de prova, o que implica em acréscimo na resistência mecânica.

Através de testes químicos preliminares realizados no ITI, foi verificado que o $\mathrm{Du}$ raform Polyamide é resistente a uma grande classe de soluções orgânicas como gasolina, thinner, álcool, acetona, éter etílico, diesel e querosene e soluções inorgânicas como ácidos clorídricos, nítrico e sulfúrico, hidróxido de sódio e hidróxido de amônia, não sofrendo alteração dimensional e visual significativa, apresentando um maior ganho de peso para os ácidos sulfúrico e nítrico, gasolina e thinner.

\section{A exportação de dados do PC para a máquina e as ferramentas para prototipagem}

O modelo sólido gerado no sistema CAD deve ser então convertido para a representação em malhas de triângulos com vetores normais aos triângulos e apontando para fora da estrutura, gerando um arquivo com a extensão STL que se tornou um padrão para a exportação de dados para equipamentos de prototipagem rápida, veja o modelo da prótese na Figura (7). A exportação de dados em STL está disponível na grande maioria dos sistemas $\mathrm{CAD}$, inclusive os de baixo custo.

Como qualquer outro padrão para representação geométrica, muitas irregularidades estão associadas à maneira de representar a geometria, como furos, partes sobrepostas ou lacunas nos limites das superfícies, além das imperfeições intrínsecas devido ao número limitado de triângulos na malha de representação das formas geométricas. Para tratar destas irregularidades existem algumas ferramentas comercialmente disponíveis para a manipulação dos arquivos STL, validando os mesmos e reparando os problemas usualmente encontrados.

A manipulação referida é possível através do uso de ferramentas de visualização com sombreamento e dimensionamento da peça. A quantidade e qualidade de triângulos em um arquivo STL pode ser otimizada, criando modelos mais precisos e realísticos e que utilizem menor quantidade de memória e processamento. Finalmente, o modelo STL tem que ser fatiado por esta ferramenta gerando comandos específicos para confecção no equipamento de prototipagem.

Estas ferramentas incorporam recursos para compensar as mudanças na forma do protótipo, devido à contração e as deformidades intrínsecas dos processos de prototipagem rápida, ou para compensar um revestimento posterior ou, ainda, trabalhos de acabamento.

Outros recursos destas ferramentas permitem a união de diferentes modelos em STL criando um modelo composto e a mudança da forma do modelo, como inserção de furos, criação de pinos de união, cortes de partes do modelo, etc. Com estas ferramentas é possível a criação de modelos ocos e superfícies finas, otimizando tempo e material gastos, levando em consideração a redução de problemas de deformação. Nos processos baseados em líquido é necessário uma ferramenta para a geração automática das estruturas de suporte. 


\section{Montagem do Build}

A etapa seguinte à verificação da consistência dos arquivos de malhas triangulares que representam as várias peças ou protótipos é a montagem do volume de trabalho ou build, onde as peças estarão sendo sinterizadas. Os vários protótipos são distribuídos dentro de um espaço cilíndrico de $300 \mathrm{~mm}$ de diâmetro por
$320 \mathrm{~mm}$ de altura, levando em consideração a otimização do espaço, de modo a caber o maior número possível de peças e o plano de construção do protótipo, o que confere maior ou menor resistência à certas áreas ou detalhes do protótipo, veja Figura (8). Além disso, são considerados os eixos de montagem de modo a manter a precisão uniforme nos eixos $X, Y$ e $Z$ de cada peça.

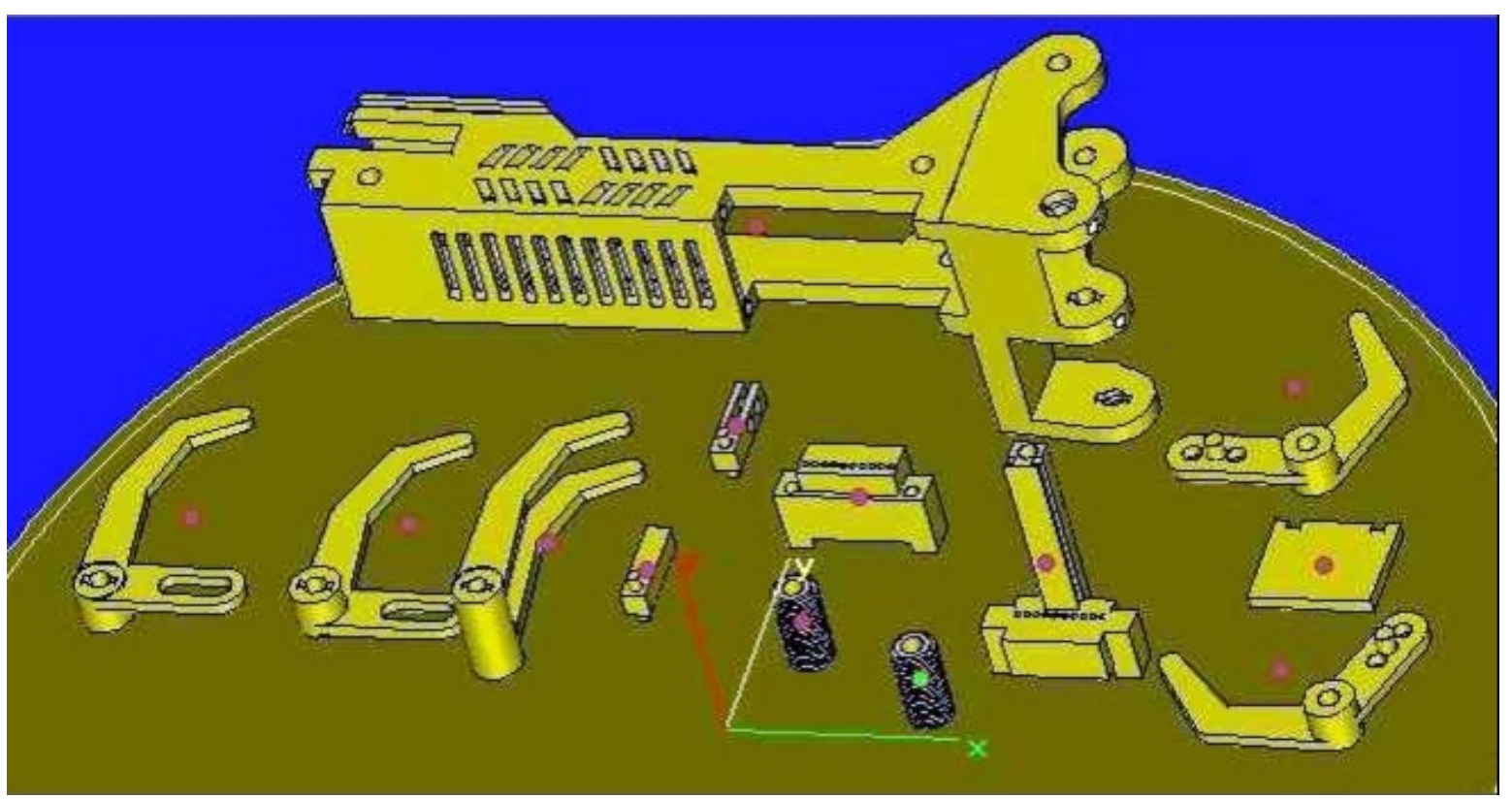

FIGURA 8: Build virtualmente montado com as peças da prótese na plataforma.

\section{Sinterização a Laser Aplicada em cada plano do Projeto da Prótese}

Existem vários processos de prototipagem rápida disponíveis comercialmente e utilizados nos vários setores industriais, principalmente no setor automotivo mundial. Apesar de ser recente, o primeiro protótipo foi apresentado nos meados da década de 80. Esta tecnologia tem crescido significativamente no contexto mundial com o aparecimento frequente de novas patentes, processos e sistemas comerciais. A motivação para o desenvolvimento desta prótese tem sido a ampla faixa de aplicações que passam a ser vislumbradas com a possibilidade de se obter diretamente de um mo- delo virtual um objeto físico com as mesmas características geométricas e que, em grande parte das aplicações, pode ser utilizada como protótipo funcional de forma a validar o projeto com um significativo aumento na sua qualidade e tempo de desenvolvimento, e com redução de custos [6] 8 .

Naturalmente, cada processo tem peculiaridades que o torna ou não mais adequado à construção de um protótipo. Os processos mais amplamente utilizados são: os processos que utilizam resina líquida com a solidificação provocada por exposição a lasers ultravioleta, como a SLA, os processos que utilizam póstermoplásticos sinterizáveis, como a SLS, e os processos que utilizam a extrusão de um fio de material termoplástico, como a modelagem 
FDM. É importante ressaltar que devido às características de cada processo como precisão, custos e qualidade do material do protótipo, o processo melhor indicado é o que atende aos requisitos de produção com os menores custos e tempo. No processo SLS, indicado na Figura (9), uma fina camada de pó termofundível é depositado sobre uma superfície com a ajuda de um rolo. Um feixe de laser de $\mathrm{CO}_{2}$ sinteriza as áreas selecionadas causando a aderência do pó nas áreas da peça a ser formada naquela camada em particular.

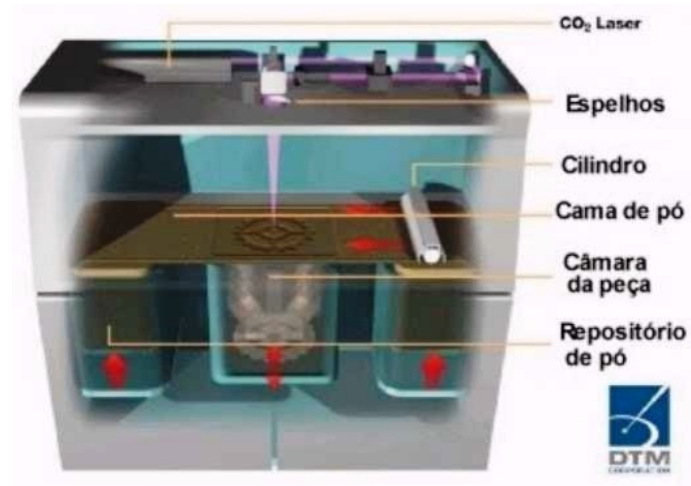

FIGURA 9: Processo SLS para prototipagem rápida, cortesia da DTM Corp. .

Deposições sucessivas de camadas são feitas até que a peça esteja completa. O pó não sinterizado (fundido) pelo laser que servia como uma estrutura de suporte para partes salientes e desconectadas é removido quando a peça estiver completa.

A diversidade de materiais incluindo compóstos metálicos que podem ser usados em SLS é significativa quando comparado à outros processos. Alguns materiais disponíveis são: nylon, cera, poliamida, elastômero, cerâmica e metal com polímero aglutinante para aplicações em ferramental rápido.

\section{Obtenção da Montagem Final da Estrutura da Prótese}

Após o processo de SLS, o conjunto de peças da prótese e também os corpos de provas do material, quando requeridos, são retirados do cilindro passando por um tempo de resfriamento à temperatura ambiente. No final deste processo o excesso de pó aglutinado na superfície, detalhes e furos das peças são removidos. Então, as peças sofrem um jateamento de areia para a remoção do material pó em locais de difícil acesso.

No processo seguinte, as peças são montadas, umas nas outras, obtendo-se a forma da estrutura da prótese na sua montagem final, conforme ilustrado na Figura (10). Nesta fase alguns excessos tais como problemas de sobredimensionamento, ou causados por detalhes de projetos, podem ser removidos com uma lixa fina. Mas, caso seja necessário, o projeto deve ser reiniciado e corrigido.

\section{COMPARAÇÃO DOS RESULTADOS OBTIDOS}

Com o objetivo de dominar a produção de alguns protótipos de próteses antropomórficas, após diversos estudos sobre a anatomia e biomecânica e fisiologia do sistema nervoso, produzimos um protótipo dos membros superiores que permitiu o surgimento de muitas idéias sobre o funcionamento, o formato e o modelo antropomórfico.

Deste estudo partimos para a construção de alguns modelos por processo de otimização como encontrados na literatura. A buscada otimização está inovando também a parte eletrônica, onde além da prototipagem rápida, caminhamos também para a sintetização dos circuitos com o emprego de dispositivos reprogramáveis, conforme [17. Ao final deste trabalho obtemos as estruturas de dois protótipos: um em Duraform Polyamide por prototipagem e o segundo em alumínio, conforme mostram as Figura (11) e Figura (12).

O protótipo da prótese infantil em alumínio ficou com um peso além do permitido pela norma [18. Mas verificamos que a retirada de massa através de furos em alguns pontos poderá resolver este problema.

A partir da usinagem e dos testes de algumas peças o projeto da prótese de alumínio foi 
refeito, pois as forças a que as peças ficaram submetidas durante a fabricação bem como em alguns ensaios mostraram ser capazes de destruí-las ou danificá-las, comprometendo o bom funcionamento e a durabilidade das mesmas. Isto pode ser verificado, por exemplo, na fabri- cação das âncoras dos cabos de fios de SMA e eixos das juntas. Quando o processo de prototipagem rápida é utilizado não há danos às peças, embora algumas peças críticas tenham se mostrado frágeis neste processo, é o caso das conexões da mola e do êmbolo atuador.
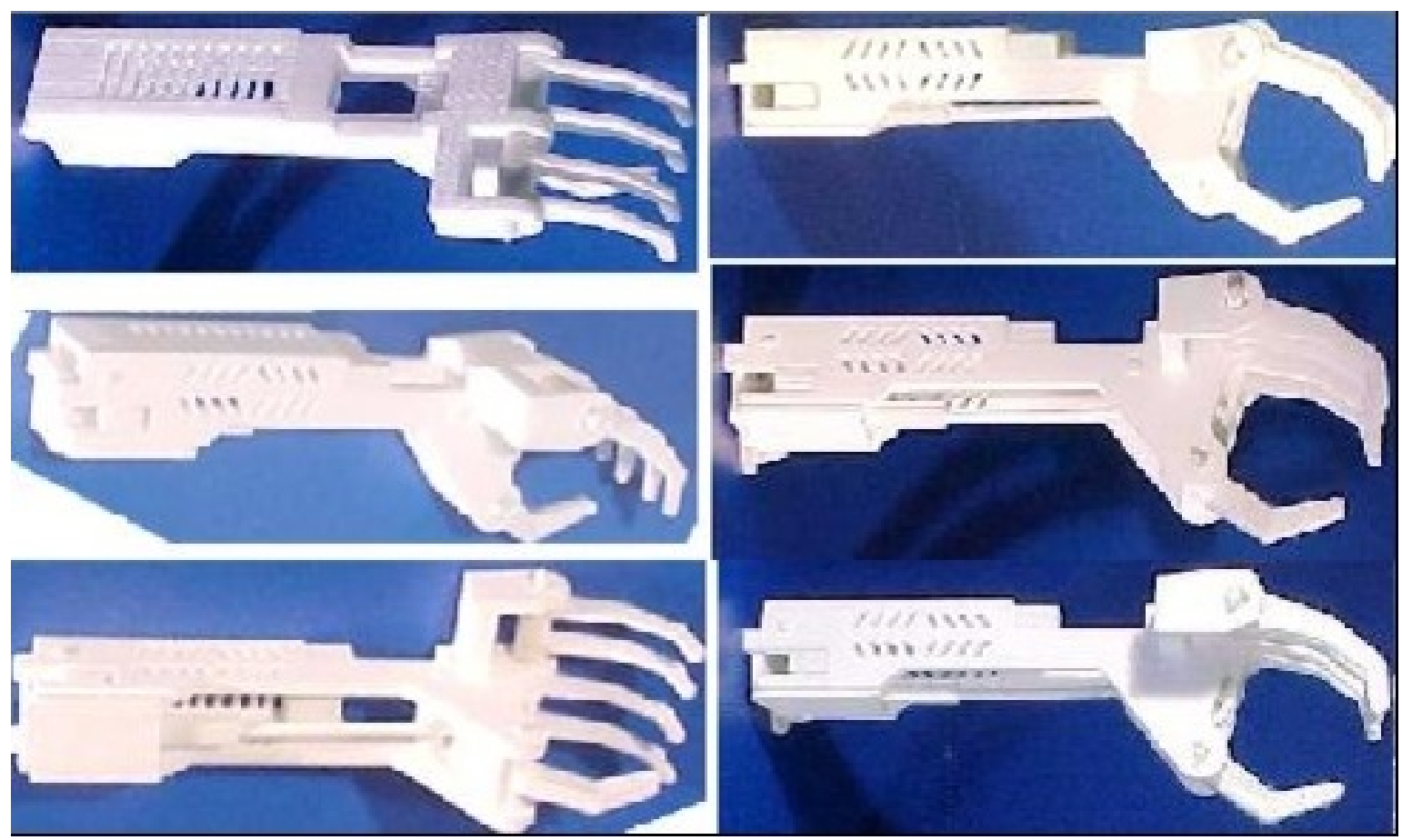

FIGURA 10: Prótese obtida no final do processo vista por diversos pontos de vista.

O emprego da prototipagem rápida apresenta-se promissor, pois o material nele empregado tem consistência, peso e resistência compatíveis com a resistência e capacidade orgânica, veja as normas [18, muito embora não sejam naturalmente renováveis.

A prototipagem rápida apresenta outra vantagem relativa à necessidade de alterações do projeto estrutural, pois fica extremamente fácil a alteração do projeto e a produção de outra peça a partir dele. Outra vantagem é a qualidade do produto que é razoável devido a precisão e padrão do equipamento.

A prototipagem rápida permitiu a fusão de algumas peças que no caso da usinagem requeria a separação delas para que as ferramentas pudessem executar algum detalhe interno. Esta fusão das peças estabiliza e padroniza a estrutura da prótese e elimina alguns pontos de travamento das peças móveis.

A usinagem da prótese de alumínio se dá através de máquinas convencionais, e não foi tão precisa. A usinagem de mini-dispositivos como a prótese referida requer a utilização de máquinas de alta precisão, o que encarece o produto final e requer uma análise do custo benefício.

\section{CONCLUSÕES E CONSIDERAÇÕES FINAIS}

O objetivo de vislumbrar novas técnicas e de descobrir novos materiais para a produção de próteses, foi atingido com a otimização deste projeto, e verificamos como as técnicas da física tem contribuído para isto.

A produção do modelo em alumínio por 


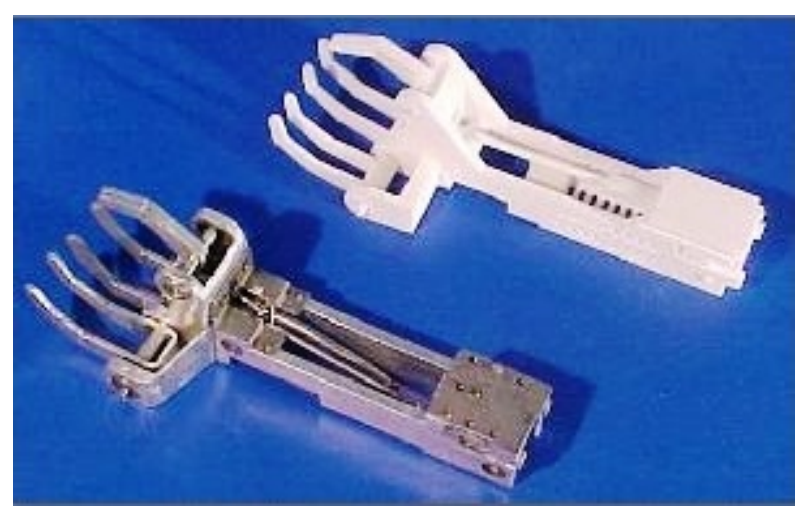

FIGURA 11: Vista superior das estrutura dos protótipos produzidos por Duraform Polyamide e alumínio.

usinagem requer o uso de pessoal especializado e necessita de máquinas de usinagem com maior precisão. Em particular, verificamos que o alumínio por ser maleável dificulta o acabamento, especialmente as pequenas peças podem ser deformadas e aquelas que requerem roscas para passagem de parafusos podem ter as roscas espanadas, inutilizando assim a peça.

$\mathrm{O}$ uso da prototipagem rápida já pode ser acessada em alguns centros de pesquisa nacionais, permitindo a produção de protótipos e moldes para a produção de próteses funcionais, com a vantagem de facilitar a adaptação em um único projeto de prótese em diversos usuários, e associado aos scanners espaciais, podem facilitar a reengenharia dos soquetes e da estética das próteses.

Seguindo a idéia do parágrafo anterior, sugerimos aqui como projeto futuro a construção de uma prótese onde o atuador seja um motor elétrico, do tipo corrente contínua ou de passo, onde apenas a estrutura do atuador deste projeto apresentado, ou seja o ante braço seria substituído por um pequeno, moderno e robusto motor, o que tornaria esta prótese indicada também para crianças portadores de amputação a nível de punho.

Com este trabalho podemos vislumbrar que a prototipagem rápida pode ser empregada, não só na construção de próteses com materiais mais firmes, mas também na construção de soquetes, empregando materiais mais flexíveis.

Olhando mais adiante, esperamos que através das experiências adquiridas neste programa, se possa experimentar outros tipos de acionamentos além dos motores elétricos e a SMA. Que sejam experimentados atuadores pneumáticos rígidos e flexíveis e se possível um solenóide. E sobre as estruturas das próteses sejam de diferentes modelos, onde cada dedo ou junta possa ser acionados isoladamente.
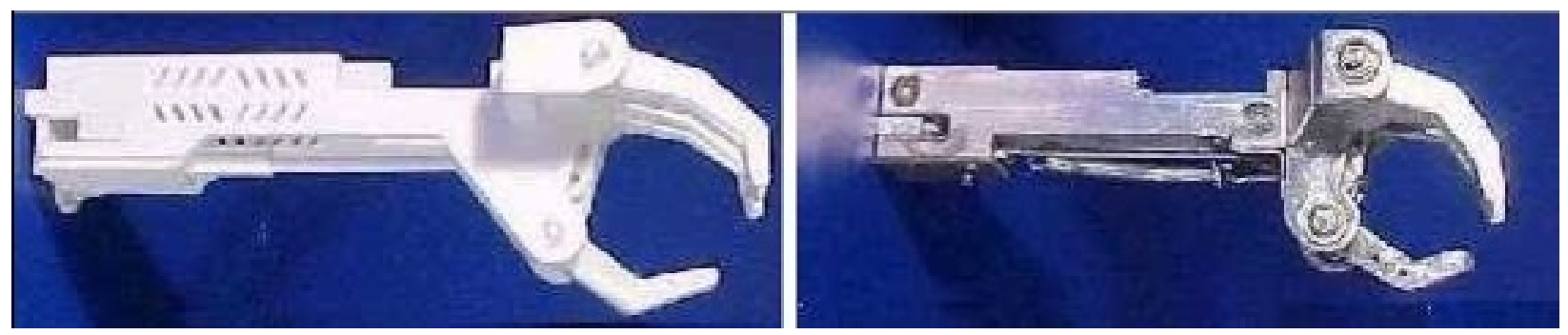

FIGURA 12: Vista lateral das estruturas dos protótipos produzidos por Duraform Polyamide e alumínio.

\section{Agradecimentos}

À Fundação de Amparo à Pesquisa do Estado de São Paulo (FAPESP) pelo suporte financeiro, ao técnico Richard do CEMPRA pelo apoio no projeto, e ao torneiro Maurício do DPM-FEM-UNICAMP pela usinagem do projeto da prótese. E, em especial, ao profes- sor Carlos Theodoro da Universidade Federal do Ceará (UFC) por gentilmente ter cedido as ligas de SMA para nossos estudos.

APÊNDICE A: SIMBOLOGIA DO TEMA 
SMA - Shape Memory Alloy ou Metal com Memória de Forma.

CAD - Computer Aided Design - Projeto Auxiliado por Computador.

SLS - Selective Laser Sintering - Sinterização Seletiva a Laser.

ITI - Instituto Nacional de Tecnologia da Informação.

PSC-MA - Produção de Soquetes por Complementação Baseado em Mapeamento Anatômico.
PPR - Processo de Prototipagem Rápida.

CAE - Computer Aided Engineering - Engenharia Auxiliada por Computador.

SLA - Estereolitografia.

FDM - Modelagem por Deposição de Fundido.

CC - Corrente Contínua.

STL - Formato de Arquivo para Prototipagem Rápida.

NWU - Nothwestern University.

[1] A.B. Soares, Shape Memory Alloy Actuators for Uper Limb Prostheses. Thesis (Doctoral) University of Edinburgh, Edinburgh (1997).

[2] C. Eyzaguirre, S.J. Fidone, Fisiologia do Sistema Nervoso. Rio de Janeiro: Guanabara Cougan (1977).

[3] W. Kapit, M.L. Elson, Anatomia: Manual para Colorir. São Paulo: Harper \& Row do Brasil. (1977).

[4] A.P. Spence, Anatomia Humana Básica. São Paulo: Manoelle Ltda. (1991).

[5] S. Hall, Biomecânica Básica. Rio de Janeiro: Guanabara Cougan II (1991).

[6] N.C. Silva, J.V.L. da Silva, C.R.E. Lima, J.M. Rosário, Estudo, Desenvolvimento e Processo de Fabricação de Próteses Antropomórficas Ativas destacando a Prototipagem Rápida e a Usinagem. In: Congresso Brasileiro de Engenharia Mecânica (Cobem), 2001. Uberlândia (2001).

[7] N.C. Silva, J.V.L. da Silva, J.M. Rosário, Construção Estrutural de Póteses Antropomórficas Utilizando Prototipagem Rápida. In: Congresso Brasileiro de Engenharia Mecânica (Cobem), 2001. Uberlândia (2001).

[8] N.C. Silva, J.V.L. Da Silva, M.F. Gouveia, J.M. Rosário, Desenvolvimento Rápido de Próteses Antropomórficas Utilizando Prototipagem Rápida e Sistemas CAD. In: Iberian Latin-American Congress on Computational Methods in Engineering, $22^{t h}$, and Brazilian Congress on Computational Mechanics, $2^{\text {nd }}$, Proceedings, 2001. Campinas (2001).
[9] M.W. Spong, M. Vidyasagar, Robot Dynamics and Control. New York: John Wiley \& Sons (1989).

[10] J.J. Craig, Introduction to Robotics: Mechanics and Control. New Jersey: Prentice Hall, $2^{\mathrm{a}}$ ed. (1989).

[11] N.C. Silva, J.M. Rosário, A.G. Badan Palhares, Seleção de Atuadores e Acionamento de Juntas Robóticas Integrada à Modelagem Dinâmica de Manipuladores Industriais. Tese (Doutorado) - Faculdade de Engenharia Elétrica e de Computacão da UNICAMP, São Paulo (1998).

[12] N.C. Silva, J.M. Rosário, Introduction to Intermediary Frame Concept, for the Analytic Study of the Kinematics models in Anthropomorphic Limb and Prostheses. In: World Congress on Medical Physics and Biomedical Engineering, Proceedings, 2000. Chicago (2000).

[13] N.C. Silva, J.M. Rosário, Influência de Particularidades da Cinemática dos Membros Superiores Antropomórficos na Comunicação Cotidiana por Gestos. In: Congresso Nacional de Engenharia Mecânica (CONEM), Anais, 2000. Natal (2000).

[14] N.C. Silva, J.M. Rosário, Modelagem Cinemática Analítica Completa do Corpo Humano e das Potenciais Próteses dos Membros. In: Congresso Brasileiro de Automação, Proceedings, 2000. Florianópolis (2000).

[15] D.S. Childress, Eletric Humeral Rotator, (2000). Página da Internet http://www.repoc.nwu.edu/. 
[16] A. Dolenc, An Overview of Rapid Prototyping in Manufacturing. Helsinki: Institute of Industrial Automation, Helsinki University of Technology (2000). Página da Internet: http://www.cs.hut.fi/ ado/rp/rp.html.

[17] C.E. Lima, N.C. Silva, J.M. Rosário, $A$ Proposal of Flexible Architecture for Mobile Robotics. In: Mechatronics Forum International Conference and Mechatronics Education Workshop, $7^{\text {th }}$, Proceedings, 2000. Atlanta: (2000).

[18] São Paulo. Normas Técnicas, Fabricação e Representação de Próteses
(1999). Jaú - SP. Página da Internet: http://www.biomecanica.com.br.

[19] K. Hennou, J.C. Lafort, Controle d'une Prothese de Genou. In: World Congress on the Theory of Machines and Mechanisms, $10^{t h}$, Proceedings, 1999. Finland: Oulu (1999).

[20] JTEC/WTEC, Panel Report on Rapid Prototype in Europe and Japan. (2000). Página da Internet: http://www.itri.loyola.edu/rp/.

[21] Rapid Prototype, 2000. Página da Internet: http://www.cc.utah.edu/asn8200/rapid.html. 